\title{
RAMIÓ, Carles: Inteligencia Artificial y Administración Pública: Robots y humanos compartiendo el servicio público
}

\section{RAMı́, Carles: Inteligencia Artificial y Administración Pública: Robots y humanos compartiendo el servicio público}

\author{
Raúl Enrique Rigo \\ Ministerio de Economia, Provincia de Buenos Aires (Argentina) \\ rigoraulenrique@gmail.com
}

\begin{abstract}
NOTA BIOGRÁFICA
Máster en Gestión Pública en América Latina (Universidad Pompeu Fabra, Barcelona, España, 2018). Graduado en Alta Dirección (Instituto de Altos Estudios, Universidad Austral, Argentina, 2009). Licenciado en Economía (Universidad de Buenos Aires, 1993). Asesor del Ministro de Economía de Buenos Aires y del Senador Provincial ante el Congreso Nacional. Especialista en Gestión Financiera Gubernamental orientada a resultados y en innovación pública.
\end{abstract}

\section{RESUMEN}

Recensión del libro de Ramió, Carles, Inteligencia Artificial y Administración Pública: Robots y humanos compartiendo el servicio público. Los libros de la Catarata, 2019, 176 páginas.

\section{PALABRAS CLAVE}

Administración pública; inteligencia artificial; seguridad jurídica; innovación; valores públicos.

\begin{abstract}
Review of the book from Ramió, Carles, Inteligencia Artificial y Administración Pública: Robots y humanos compartiendo el servicio público. Los libros de la Catarata, 2019, 176 pp.
\end{abstract}

\section{KEYWORDS}

Public administration; artificial intelligence; legal certainty; innovation; public values.

En su prolífica obra, el Profesor Carles Ramió Matas se ha referido, en varias ocasiones, a una tensión que suele plantearse con frecuencia en los ámbitos públicos de muchos países: por un lado, la necesidad de fortalecer los principios de eficiencia y flexibilidad en la gestión pública, promovida -entre otros- por las visiones próximas a la Nueva Gestión Pública; por otro, la importancia de mantener el apego a los principios burocráticos, postulado próximo y afín a los cuerpos de empleados y sindicatos públicos. Esta tensión se generaría porque estos principios burocráticos, que tienen un rol clave como garantes de la institucionalidad y la seguridad jurídica, suelen ser arietes -al mismo tiempo- de intereses burocráticos y sindicales corporativos para obstaculizar los procesos de reforma de la administración pública, bloqueando la innovación y demorando la incorporación de tecnología en las rutinas administrativas de la administración pública. En definitiva, pareciera que los beneficios de la eficiencia y la eficacia en la gestión de los asuntos y servicios públicos «mueren» a manos de los presuntamente anquilosados principios postulados por Maximilian Karl Weber a principios del siglo $x \mathrm{x}$. 
En este contexto, el libro "Inteligencia artificial y administración pública: Robots y humanos compartiendo el servicio público", del Profesor Ramió, propone -en clave política e institucional- ponderar los avances de la inteligencia artificial y de la robótica como enormes posibilidades para consolidar -en el sector público- un nuevo modelo de cultura y administración pública que provoque la renovación tanto de la cultura administrativa imperante como de los modelos de gestión (burocrático, gerencial y de gobernanza). Sigue postulando el Profesor Ramió que dicha renovación debería tratar de potenciar -mediante la aplicación plena de los principios burocráticos- la inteligencia institucional de unas organizaciones públicas vigorosas, capaces de erradicar el clientelismo y la corrupción. Eso permitiría avances en términos de transparencia y calidad de los servicios públicos que se brindan a los ciudadanos.

La adopción de la inteligencia artificial y la incorporación de robots en la administración pública planteada en términos gerenciales y prácticos es, sin lugar a dudas, el aspecto más original de la aportación del Profesor Ramió tendiente a modelar una administración pública capaz de interactuar con un mundo cuyos paradigmas políticos, sociales y económicos están cambiando de manera vertiginosa. En efecto, autores como Max Tegmark, Elon Musk o Steven Finlay han delineado interesantes y similares prospectivas respecto de la transformación del mundo de los negocios al incorporar la inteligencia artificial y la robótica en el mundo empresarial.

El libro "Inteligencia Artificial y Administración Pública: Robots y humanos compartiendo el servicio público" se estructura en 10 capítulos en los que se reflexiona y se realizan aportaciones en tres ámbitos: uno más abstracto o conceptual, otro más pragmático o gerencial y, el más inquietante -según mi parecer-el ámbito tecnológico.

Los aspectos conceptuales se abordan en los capítulos 1 ("La smartificación y robotización de la administración pública"), 2 ("La renovación de los modelos de gestión y de la cultura administrativa"), 3 ("Un nuevo modelo organizativo para la administración pública"), 8 ("La gobernanza pública de la inteligencia artificial y de la robotización") y 10 ("La organización del futuro empleo en la administración pública: robots y humanos compartiendo el servicio público"). En este ámbito conceptual el profesor Ramió aborda la cuestión de la necesaria renovación de los modelos de gestión existentes (burocrático, gerencial y de gobernanza) $y$, en particular, de las culturas administrativas asociadas a cada uno de ellos. En tal sentido, reflexiona y propone un nuevo modelo organizativo de la administración pública formateado sobre once principios generales. Mencionamos sólo algunos de ellos, para transmitir el espíritu de la propuesta: «orgullo por defender los valores públicos y por trabajar en el sector público», "autogestión en el marco de la jerarquía», «más visión política y más complicidad con la política», «profesionalización y lucha contra el clientelismo», «sencillez frente a lo complejo», entre otros. Principios que, señala Ramió, perfilarán «una administración pública líquida, abierta, colaborativa pero sólida, predecible y constante».

Estos principios fundantes de un nuevo modelo organizativo de la administración pública promoverían, a su vez, nuevos principios que deberían regir el empleo público del futuro. En su prospectiva, el profesor Ramió postula, entre otros, los siguientes: empleados «abiertos a la introducción de la inteligencia artificial», empleados capaces de "asumir con naturalidad que robots y humanos van a trabajar conjuntamente» y de «abordar con solvencia los nuevos puestos profesionales vinculados a la inteligencia artificial y a la robótica».

Para terminar de perfilar el modelo de administración pública del futuro, el libro hace una enumeración de las tareas típicamente burocráticas que podrían ser asumidas por robots: gestión administrativa de expedientes de tramitación burocrática, mantenimiento y limpieza, gestión de redes organizativas y muchas más.

Por último, el Profesor Ramió reflexiona que la gobernanza pública del desarrollo de la smartificación y de la robótica es una condición sine qua non del desarrollo del nuevo paradigma público. En tal sentido, identifica la necesidad de que los algoritmos de la inteligencia artificial sean diseñados con cautela, en particular aquéllos que manipulan los datos sensibles para las personas y así evitar marginaciones, sesgos u opacidades en el accionar de la administración pública. Para ello, se propone la creación de una agencia gubernamental, de naturaleza regulatoria, capaz de evaluar dichos algoritmos y de asegurar condiciones mínimas de transparencia. En definitiva, se considera que las administraciones públicas deberían cumplir un rol decisivo para promover la industria de la robótica y de la inteligencia artificial, regulando su desarrollo e impacto tanto en la esfera pública como en la privada.

Las aportaciones en el plano tecnológico son -según mi criterio- un aporte sumamente original. Además, confieren a la obra un allure, ciertamente, de ciencia ficción próxima e inquietante, y nos anticipan un mundo público diferente y pletórico de oportunidades para la sociedad, que nos espera a la vuelta de la 
esquina. Los capítulos que se ocupan de este tema son el 4 ("La robotización de la burocracia"), el 5 ("La smartificación y robotización de la gestión"), el 6 ("La smartificación de la gobernanza público-privada") y el 7 (“La smartificación de la gobernanza política y social").

Dice el Profesor Ramió: «La automatización y la inteligencia artificial representan los catalizadores tecnológicos para lograr la calidad institucional y el buen gobierno desde una perspectiva burocrática» porque facilitarían la aplicación objetiva y no discrecional de los principios burocráticos a las rutinas públicas. Esta afirmación destaca el rol crucial, como ya se ha dicho, que nuestro autor asigna a dicho modelo burocrático de gestión pública para que un país pueda ofrecer seguridad institucional y jurídica. Pero también nos recuerda que la burocracia puede ser "altamente contaminante y tóxica» cuando invade e inmoviliza las administraciones públicas.

Así, se propone la (taquillera) idea de Gestión Pública 4.0 caracterizada por la delegación de las actividades transaccionales a las nuevas tecnologías inteligentes para, de esa manera, optimizar la gestión y gobernanza públicas y fortalecer la inteligencia y la transparencia institucionales.

La calidad institucional y el buen gobierno conllevan la necesidad, señala el libro, de aplicar también los lineamientos de la smartificación tanto a la gestión de las redes complejas de gobernanza como a la gobernanza política y social. Además, se razona que liderar la automatización de los procesos (un inevitable paso hacia la smartificación y la introducción de la robótica en el mundo público) conlleva múltiples dificultades. Sobre esta cuestión -enorme desafío para las organizaciones públicas que deciden modernizarse para dar respuesta a las crecientes demandas que plantean la política, la sociedad y la economía- haré una reflexión más abajo.

En el plano gerencial, el capítulo 9 (“El empleo público: desaparición y creación de nuevos perfiles profesionales") del libro del Profesor Ramió completa el ejercicio de prospectiva detallando los puestos y perfiles de profesionales públicos que podrían desaparecer. También se identifican aquéllos menos plausibles de ser reemplazados por robots.

El proceso que se anticipa tiene la dinámica propia de las épocas de cambio de paradigma por lo que mientras, seguramente, desaparecerán al menos diez tipos de tareas rutinarias, se crearán nuevas tareas, en especial aquéllas derivadas del proceso de smartificación, de la robótica, de la internet de las cosas, de la impresión 3D, entre otras disciplinas.

Por último, se postula que la revolución de la inteligencia artificial generará cambios substanciales no solamente en la organización del empleo público sino también en los sistemas tradicionales de organización del sistema político e institucional, enfatizando en la necesidad de asegurar el liderazgo político de los procesos de participación ciudadana a fin de garantizar los principios de la democracia y la libertad.

\section{¿CÓMO PUEDE UNA ORGANIZACIÓN PÚBLICA IMPLEMENTAR UN PLAN DE AUTOMATIZACIÓN DE PROCESOS ADMINISTRATIVO-BUROCRÁTICOS?}

Se señaló más arriba que la automatización y robotización de las rutinas administrativas consitituirían uno de los primeros retos para las administraciones públicas que se embarcara en procesos de reforma, innovación y de incorporación de tecnología. En tal sentido, se propone en este apartado destacar y discutir sobre las condiciones y criterios de éxito que el Profesor Ramió identifica para este reto.

Como en cualquier proyecto de envergadura (y ése sería el caso del que nos ocupa en este apartado) los incentivos de los actores que participan en el proceso son claves para el éxito (o el fracaso) del proyecto. Así, los líderes políticos de las organizaciones públicas bien podrían preguntarse cómo asegurar una buena probabilidad de éxito en esta procelosa empresa y, en particular, cómo garantizar que los buenos resultados obtenidos contribuyan a afianzar la institucionalidad, la seguridad jurídica y la equidad. Una respuesta a esta inquietud podría ser esbozada a partir del análisis, en particular, de cuatro de los ya aludidos «Once principios generales sobre los que debería asentarse la nueva administración» que desarrolla Carles Ramió Matas en el tercer capítulo de la obra que estamos comentando.

Entonces, sostener estos cuatro principios daría a políticos, ciudadanos y funcionarios públicos los incentivos necesarios para promover y respaldar la adopción de la inteligencia artificial y de la robótica en las administraciones públicas. A continuación, destacaremos esos cuatro principios rectores de la acción reformadora de la administración pública y haremos un acotado aporte a la discusión sobre sus condiciones de aplicabilidad. 
GAPP. Nueva Época - N. ${ }^{\circ}$ 22, noviembre-abril 2019 - ISSN: 1989-8991 - DOI: 10.24965/gapp.i22.10666 - [Págs. 140-144]

RAmı́́, Carles: Inteligencia Artificial y Administración Pública: Robots y humanos compartiendo el servicio público

Raúl Enrique Rigo

\section{Principio 1. La administración pública puede dar respuestas creativas a las nuevas demandas de la sociedad}

El Profesor Ramió señala que «...hay que reformular el discurso para que quede claro que la administración pública es creativa e innovadora... (que los empleados públicos) trabajan para defender el bien común y el interés general en tiempos convulsos socialmente». Esta expresión parece orientada -en especial- para los propios empleados públicos, para empoderarlos en el ejercicio de su función; considero, no obstante, que los primeros en estar convencidos de esta afirmación deberían ser los líderes políticos de las administraciones públicas, frecuentemente enredados en «mixed-feelings» respecto del rol de la administración pública y de cómo gestionarla en pos del bien común.

\section{Principio 2. Se deben fortalecer los principios burocráticos (en el sentido weberiano del término) pero los burócratas no son los aliados del proceso de reforma de la administración pública}

En segundo lugar, el mismo libro se refiere a la «Smartificación y robotización de la gestión» subrayando lo siguiente: «El problema reside en que las administraciones públicas poseen procesos administrativos poco racionales y se considera que antes de la digitalización hay que realizar una labor de reingeniería... que genera) resistencia al cambio entre los empleados». Creo que en este punto, en las administraciones públicas, el escenario se presenta, frecuentemente, al revés: la ingeniosa burocracia suele ejercer su resistencia volviéndose exquisitamente purista (de las normas, de los procesos y de los procedimientos), justamente, para boicotear las innovaciones y desgastar a las autoridades que las impulsan. Los burócratas resisten persuadiendo a temerosos ministros y secretarios de estado de que la "complejidad de la cosa pública» exige lentitudes, prudencias, pruebas piloto «acotadas» y un abanico de razonables «palos en la rueda» a cualquier iniciativa que proponga alguna innovación. Entonces, lo que debe comprender el líder político -en segundo término- es que una propuesta de reforma de la administración de envergadura siempre es disruptiva del statu-quo de las burocracias públicas. Por ello, debe encontrar aliados (en el resto del arco político y en la sociedad) para llevar adelante su cometido con prestancia. El desafío de la reforma (y el del grado de movilización de los eventuales aliados) es, en este sentido, doble porque, por un lado, es necesario -como ya se ha manifestado- rescatar o revitalizar algunos principios propios del weberianismo (la meritocracia o el apego a las normas, por ejemplo) para reasegurarnos la deseada seguridad jurídica y la imparcialidad burocrática garante de igualdad de acceso de la población a los beneficios del progreso tecnológico y económico. Pero, por otro lado, la incorporación de innovaciones como la robotización, la smartificación y el gobierno electrónico darían un tiro de gracia a las interesadas (y corporativas) interpretaciones de Weber que suele hacer la burocracia estatal y acicatearía su reacción negativa a los cambios propuestos.

\section{Principio 3. La sociedad quiere participar en los procesos de decisión pública y ser tenida en cuenta en el diseño y evaluación de políticas públicas}

En tercer lugar, aparece el tema de las redes de política pública, de la participación ciudadana y de la gobernanza. En particular, cobran creciente visibilidad los reclamos -a veces inorgánicos o desordenados, aunque persistentes- de «republificación, remunicipalización y reinternalización» de los servicios públicos tercerizados o privatizados. El Profesor Ramió, hace en su libro, una reflexión muy sugestiva: «Todo parecería indicar que es un movimiento ideológico impulsado por los gobiernos locales bajo el mando de una nueva izquierda de carácter populista. Pero esto no es del todo cierto ya que el catalizador de este movimiento han sido los desproporcionados costes económicos y la mala calidad de la gestión privada de los servicios públicos locales». Y, luego se cita a Colomer (2016): «....ante problemas difíciles y en sociedades complejas, la democracia directa y participativa degenera en populismo». Ambas reflexiones, miradas en conjunto, servirían -a mi juicio- para sensibilizar al líder político en una tercera cuestión clave: la necesidad de lograr una razonable gobernanza sobre el proceso de participación ciudadana para mantener, simultáneamente, el incentivo de la ciudadanía a apoyar el proceso de reforma y a conducir la participación pública dentro de carriles efectivos. Una nueva cita del libro mencionado del Profesor Ramió resulta ilustrativa: la «remunicipalización de servicios públicos previamente tercerizados o privatizados», por ejemplo, no es un mero devaneo 
de la izquierda política sino que es una alternativa concreta, aunque compleja, para sortear el atolladero (y el consiguiente malhumor social) en el que ha caído la sociedad cuando decisiones de privatización o tercerización de gestiones han acabado con servicios públicos de pésima calidad y carísimos (que los presupuestos públicos o los usuarios ya no pueden ni quieren pagar). ¿Por qué esta alternativa es compleja?. Porque estas alternativas suelen venir acompañadas, como bien advierte Colomer, de una presión social que propone la participación directa de la ciudadanía en el diseño de las soluciones, participación que debería ser guiada -eso sí- por un claro liderazgo cívico y social (para evitar el populismo y sus derivas exóticas y amenzantes para la democracia) e instrumentada mediante soluciones técnicas solventes: big data, crowdlaw o «smart majlis» como en la reciente experiencia de Dubai mencionada en el libro del Profesor Ramió.

\section{Principio 4. Es necesario darle prestancia y sex-appeal a la propuesta de reforma de la administración pública que debería ser atractiva y prometedora en términos de servicios al ciudadano, transparencia y experiencia de los propios empleados y funcionarios públicos}

En este sentido, el Profesor Ramió trae como una novedad la propuesta formulada por Laloux (Laloux, 2016) en cuanto a la renovación del paradigma organizativo basado en los principios de autogestión, plenitud y propósito evolutivo.

En relación con esta atrayente visión, me permitiré un último comentario que podría aludir a la experiencia profesional de no pocos servidores públicos: seguramente, en muchas ocasiones se han preguntado si los valores de «servicio público» o de «brindar un servicio a la comunidad» o de «vocación por el bien público» podrían ser elementos motivadores o inspiradores en funcionarios y políticos para lograr la tan ansiada renovación de la administración pública. En el fragor de la lucha, tal vez hayan llegado a la conclusión de que su pregunta pecaba de naive.

Sin embargo, recuperar la mística de la «vocación» o del «orgullo por defender los valores públicos» como marco conceptual de una administración pública inteligente y robotizada, es una aspiración que parecieran recobrar bríos en esta fabulosa y sugerente apuesta a la renovación de la administración pública a la que nos invita el Profesor Ramió en su reciente y enjundiosa obra, de muy recomendable lectura.

\section{REFERENCIAS}

LALOUX, F. (2016) "Reinventar las organizaciones". Madrid: Arpa Editores. 